30 Braun V, Clark V. Using thematic analysis in psychology. Qual Res Psychol 2006; 3: 77-101.

31 Culliford L, Eagger S. Assessing spiritual needs. In Spirituality and Psychiatry (eds CCH Cook, A Powell, A Sims): 16-38. RCPsych Publications, 2009

32 Langlands C, Mitchell D, Gordon T. Spiritual competence: mental health and palliative care. In Spirituality, Values and Mental Health: Jewels for the Journey (eds ME Coyte, P Gilbert, V Nicholls): 173-81. Jessica Kingsley Publishers, 2007

33 Royce-Davis J. The influence of spirituality on community participation and belonging: Christina's story. Couns Values 2000; 44: 135-42.

34 Verhagen PJ, van Praag HM, Lopez-lbor Jr JJ, Cox JL, Moussaoui D. Religion and Psychiatry: Beyond Boundaries. John Wiley \& Sons, 2010.

35 Dura-Vila G, Hagger M, Dein S, Leavey G. Ethnicity, religion and clinical practice: a qualitative study of beliefs and attitudes of psychiatrists in the United Kingdom. Ment Health Relig Cult 2011; 14: 53-64.

36 Ellis MR, Vinson DC, Ewigman B. Addressing spiritual concerns of patients: family physicians' attitudes and practices. J Fam Pract 1999; 48: 105-9.

37 MacLean CD, Susi B, Phifer N, Schultz L, Bynum D, Franco M, et al. Patient preference for physician discussion and practice of spirituality. J Gen Intern Med 2003; 18: 38-43.

38 Maugans TA, Wadland WC. Religion and family medicine: a survey of physicians and patients. J Fam Pract 1991; 32: 210-3.
39 Senghera R. Equality and human rights approaches in the NHS: making spirituality in mental health care count? In Spirituality and Mental Health (ed P Gilbert): 315-34. Pavilion Publishing, 2011.

40 Hollins S. Understanding religious beliefs is our business. Invited commentary on ... Religion and mental health. Psychiatr Bull 2008; 32: 204.

41 Poole R, Higgo R. Psychiatric Interviewing and Assessment. Cambridge University Press, 2006.

42 Richards PS, Rector JM, Tjelveit AC. Values, spirituality and psychotherapy. In Integrating Spirituality into Treatment: Resources for Practitioners (ed WR Miller): 133-60. American Psychological Association, 1999.

43 Shafranske EP, Malony HN. Religion and the clinical practice of psychology: a case for inclusion. In Religion and the Clinical Practice of Psychology (ed EP Shafranske): 561-86. American Psychological Association, 1996

44 Culliford L. Teaching spirituality and health care to third-year medical students. Clin Teach 2009; 6: 22-7.

45 Gerson J, Allen R, Gold J, Kose G. Multiple belief systems in psychotherapy: the effects of religion and professional beliefs on clinical judgment. J Contemp Psychother 2000; 30: 27-32.

46 Poole R, Higgo R. Clinical Skills in Psychiatric Treatment. Cambridge University Press, 2008.

\title{
Sector and functional models of consultant care: in-patient satisfaction with psychiatrists
}

\author{
Richard Laugharne, ${ }^{1,2}$ Milind Pant ${ }^{1}$
}

The Psychiatrist (2012), 36, 254-256, doi: 10.1192/pb.bp.111.037333

${ }^{1}$ Cornwall Partnership NHS Foundation

Trust, Liskeard, Cornwall, UK

${ }^{2}$ Peninsula Medical School, Plymouth,

Devon, UK

Correspondence to Richard Laugharne (richard.laugharne@pms.ac.uk)

First received 6 Oct 2011, final revision 9 Jan 2012, accepted 29 Feb 2012
Aims and method To investigate in-patient satisfaction with psychiatrists, comparing National Health Service (NHS) trusts with sector consultants against NHS trusts with separate in-patient and community consultants (the functional model). The Care Quality Commission's in-patient survey was used, comparing mean scores on four questions concerning patient satisfaction with consultants.

Results Patients scored higher for being treated with respect in trusts with sector consultants. In questions concerning trust, being listened to and getting adequate time, patient satisfaction scores were again higher for sector consultants, but did not reach $5 \%$ significance.

Clinical implications Moving to a split between in-patient and community consultants may reduce in-patient satisfaction with care. The continuity of care with sector-based consultants may be a factor in greater in-patient satisfaction.

Declaration of interest R.L. has argued strongly to maintain the sector model at the NHS trust in which he works.
In general adult mental health services in England, there has been a recent shift from a sector model, in which the consultant psychiatrist cares for both in-patients and out-patients from one geographical area, to a model of in-patient consultants and community consultants (the functional model). ${ }^{1,2}$ This has provoked some debate among psychiatrists and mental health leaders. ${ }^{3}$ The sector model has the advantage of continuity of care in that the same consultant cares for the patient in and out of hospital. The functional in-patient/out-patient model has the advantage of avoiding many consultants feeding into an in-patient unit, with potentially better consultant leadership on wards.

Despite the heated debate, there is limited evidence to base judgements on which model might be better for 
patients and staff. A qualitative study identified perceived strengths and weaknesses of the in-patient/out-patient consultant model after a change from the sector model. ${ }^{2}$ In another study, Singhal et $a l^{4}$ asked service users and providers what they felt about a change from a sector model to an in-patient/out-patient one. Most service users and general practitioners were unaware of the change. Service providers felt that continuity of care, patient/carer satisfaction and clinical skills would be adversely affected, whereas length of stay in hospital would be reduced.

We sought to answer the following research question: is there a difference in in-patient satisfaction with psychiatrists between mental health trusts with dedicated in-patient consultants and trusts with sector consultants?

\section{Method}

The Care Quality Commission (CQC) reported on an in-patient survey of all mental health trusts in England in 2009..$^{5}$ This was a survey of people who had had an in-patient stay in acute mental health units, and had responses from over 7500 individuals. The survey asked people all about their experiences of acute in-patient mental health services along the pathway, from admission to leaving hospital, including the care and treatment they received, day-to-day activities, and relationships with staff. We used scores on the four satisfaction questions concerning psychiatrists.

1 Did the psychiatrist listen carefully to you?

2 Were you given enough time to discuss your treatment? 3 Do you have confidence and trust in the psychiatrist?

4 Did the psychiatrist treat you with respect and dignity?

The report gave a score for each trust between 0 and 100 for each question reflecting the responses of patients in that trust.

We contacted the medical directors of these trusts via email and asked whether their trust had a dedicated in-patient consultant model or a sector consultant model at the time of the CQC survey (July to December 2008). We divided the trusts into two groups (sector or in-patient/outpatient consultants) and compared the average scores on the four questions on satisfaction with psychiatrists. The average scores in each group were compared using SPSS version 13 for Windows by an independent statistician. Unpaired $t$-tests were used for comparisons of means.

\section{Results}

Overall, 64 mental health National Health Service (NHS) trusts had CQC survey reports on acute in-patient services; 34 trusts responded to the email query, but 3 did not want to share information on which of the consultant models they operated. Out of the 31 NHS trusts who did provide this information, 26 had a clear model of either a dedicated in-patient consultant $(n=10)$ or a sector consultant model $(n=16)$ at the time of the survey. The other 5 trusts either had a mixed model or had changed their model during the period of the survey. Only the 26 trusts that had a clear dedicated in-patient consultant or a sector consultant model at the time of the survey were included.

The results of the survey are presented in Table 1 . The mean satisfaction scores for each question oscillated around 6-8 (where 0 was the worst possible score and 10 was the best). On only one question (number 4 ) did the difference between the two models of service reach the $5 \%$ significance level at 0.011. When calculating the mean score for all four questions for the two groups (Fig. 1; 0 - worst possible score, 10 - best possible score), the difference reached near significance at 0.06 (two-tailed $t$-test, equal variance not assumed).

It is interesting to observe that the standard deviations are higher for the sector model, which may suggest that the sector model might lead to a greater variability in performance of consultants.

\section{Discussion}

These findings suggest a trend towards in-patient satisfaction for consultant psychiatrists working in a sector model rather than the functional in-patient/community split model. Only one question reached a statistically significant difference at a $5 \%$ level, but the trend was consistently in favour of the sector model (Table 1).

There are clear limitations to this study. The research used secondary data from a national survey, and the

Table 1 Statistical results of the 4-question survey on patient perception of psychiatrists in 26 National Health Service
trusts in England and Wales

a. Two-tailed $t$-test, equal variance not assumed. 


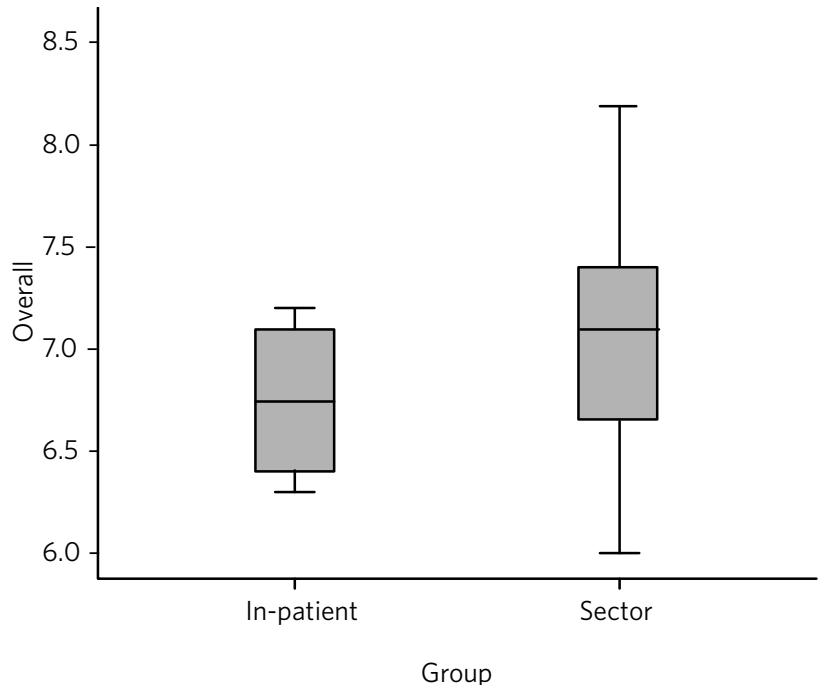

Fig 1 Plot for mean scores on all four questions, comparing trust with sector consultants and those with in-patient consultants.

limitations in this survey must be taken into account along with the limitations in our own method. The performance of the psychiatrists was not necessarily directly related to the model of consultant care, and there may be confounding factors influencing the levels of satisfaction in psychiatrists. For example, more rural areas may have kept the sector model for reasons of distances travelled in the community (as we have in Cornwall) and patient satisfaction may be greater in rural areas as morbidity tends to be less severe. The model may be more appropriate for urban areas, where distances are small and the pressure on wards can be higher. These results are from 26 out of 64 NHS trusts in England, although there is no reason to believe the other trusts would be different to those that responded. The trend to better patient satisfaction for the sector model did not reach statistical significance in four of the five calculations. This may be a type-two error due to the small sample size.

The study presents some implications for practice. It is possible that the sector model encourages better communication with patients. We can hypothesise that sector consultants know in-patients and their families well from their contact in the community, and so trust and respect are often well established and a therapeutic relationship does not have to be built from scratch. It is also possible that the continuity of care encourages consultants to treat patients better and invest more time in the therapeutic relationship, as they will be seeing them in the future in the community. In-patient consultants may have less motivation to establish rapport if they are not responsible for future care in the short to medium term. In primary care, having a longer relationship with a physician is related to a greater therapeutic quality in the relationship. ${ }^{6}$

The implication for policy is that pushing ahead with a change from sector consultants to the in-patient/ community consultant split may not be in the best interests of patients in respect of in-patient satisfaction. A change in service delivery, which always costs money in professional time, should be expected to improve a service in some way. There may be other advantages, such as better consultant leadership on wards, but this claim would need to be backed by evidence. Ideology-based health policy is fraught with dangers.

\section{Acknowledgement}

We thank Jo Palmer for statistical advice and help.

\section{About the authors}

Richard Laugharne FRCPsych is a consultant adult psychiatrist (sector model) and community clinical director at Cornwall Partnership NHS Foundation Trust, Liskeard, and honorary clinical lecturer at the Peninsula Medical School. Milind Pant MRCPsych is an ST6 at Cornwall Partnership NHS Foundation Trust.

\section{References}

1 Dratcu L, Grandison A, Adkin A. Acute hospital care in inner London: splitting from mental health services in the community. Psychiatr Bull 2003; 27: 83-6.

2 Khandaker G, Cherukuru S, Dibben C, Ray MK. From a sector-based service model to a functional one: qualitative study of staff perceptions. Psychiatr Bull 2009; 33: 329-32.

3 Burns T. The dog that failed to bark. Psychiatrist 2010; 34: 361-3.

4 Singhal A, Garg D, Rana AK, Naheed M. Two consultants for one patient: service users' and service providers' views on 'New Ways'. Psychiatrist 2010; 34: 181-6.

5 Care Quality Commission. Mental health services 2009 survey reports. Care Quality Commission, 2010 (http://archive.cqc.org.uk/aboutcqc/ howwedoit/involvingpeoplehouseservices/patientsurveys/mental healthservices.cfm).

6 Noyes R, Kukoyi OA, Longley SL, Longbehn DR, Stuart SP. Effects of continuity of care and patient dispositional factors on the physicianpatient relationship. Ann Clin Psychiatry 2011; 23: 180-5. 